\title{
CRESCIMENTO DE MUDAS MICROPROPAGADAS DE BANANEIRA ACLIMATIZADAS NAS CONDIÇÕES DA AMAZÔNIA SUL OCIDENTAL SOB A INFLUÊNCIA DE DIFERENTES SUBSTRATOS E RECIPIENTES ${ }^{1}$
}

\author{
JANIFFE PERES DE OLIVEIRA²,FREDERICO HENRIQUE DA SILVACOSTA ${ }^{3}$,JONNY EVERSON SCHERWINSKI PEREIRA ${ }^{4}$
}

RESUMO - Para laboratórios que produzem milhares de plantas micropropagadas regularmente, a otimização da fase de aclimatização é de fundamental importância para evitar perdas excessivas de plantas, bem como favorecer seu crescimento. O trabalho teve por objetivo avaliar o crescimento de mudas micropropagadas de bananeira na aclimatização, sob a influência de diferentes substratos e recipientes, nas condições da Amazônia Sul-Ocidental. Após o sexto subcultivo, brotações de bananeira, cv. Grand Naine (AAA), foram enraizadas em meio MS básico sendo, posteriormente, transferidas para viveiro onde foram plantadas em tubetes de $115 \mathrm{~cm}^{3} \mathrm{e}$ $180 \mathrm{~cm}^{3}$ preenchidos com seis diferentes substratos, formulados a partir da combinação de terra de encosta, esterco bovino e casca de arroz carbonizada. Avaliações sobre sobrevivência, altura da parte aérea e diâmetro do pseudocaule foram realizadas quinzenalmente, sendo que, ao final de 75 dias, também foi determinada a massa fresca e seca das plantas. Observou-se que a sobrevivência das plantas não foi influenciada pelo uso de tubetes de $115 \mathrm{~cm}^{3}$ ou $180 \mathrm{~cm}^{3}$, no entanto, plantas aclimatizadas em tubetes de $180 \mathrm{~cm}^{3}$ apresentam maior crescimento em altura e diâmetro do pseudocaule e, conseqüentemente, maior acúmulo de massa fresca e seca das partes aérea e raízes, durante a aclimatização, quando comparados aos tubetes com $115 \mathrm{~cm}^{3}$ de capacidade. Entre os substratos, verificou-se que aqueles que continham esterco bovino na sua composição, proporcionaram resultados superiores quando comparados aos demais substratos testados para todas as variáveis analisadas, sendo este, portanto, um importante componente no desenvolvimento das plantas durante a fase de aclimatização.

Termos para indexação: Musa sp., micropropagação, tubetes, aclimatização, ambiente ex vitro.

\section{GROWTH OF MICROPROPAGATED BANANA PLANTLETS ACCLIMATIZED ON CONDITIONS OF SOUTH WEST AMAZON UNDER THE INFLUENCE OF DIFFERENT SUBSTRATES AND RECIPIENTS}

\begin{abstract}
For laboratories that produce thousands of micropropagated plants regularly, the optimization of the acclimatization phase is of fundamental importance to avoid excessive losses and to promote the development of the plants. The aim of this work was to evaluate the growth of micropropagated banana plantlets during the acclimatization under the influence of different substrates and recipients on conditions of South West Amazon. Shoots of banana, cv. Grand Naine, were rooted in MS medium, being the rooting plants transferred to a nursery, in two types of plastic dibble tubes $\left(115 \mathrm{~cm}^{3}\right.$ and $\left.180 \mathrm{~cm}^{3}\right)$ and six different substrates formulated from different portions of soil, carbonized rice hulls and bovine manure. Evaluations of plant survival, height of the aerial part and pseudostem diameter were carried out each fifteen days, and at the end of 75 days, fresh and dry mass for the roots and aerial parts of the plants were also determined. It was verified that the plant survival was not influenced by the use of the $115 \mathrm{~cm}^{3} \mathrm{or}_{180} \mathrm{~cm}^{3}$ plastic dibble tubes. However, acclimatization accomplished in the $180 \mathrm{~cm}^{3}$ plastic dibble tubes provided larger growth in height and pseudostem diameter of the plants and, consequently, larger accumulation of fresh and dry mass of roots and aerial parts, when compared to the $115 \mathrm{~cm}^{3}$ plastic dibble tubes. Among the substrates, it was observed that bovine manure was fundamental as substrate component to obtain the best results.
\end{abstract}

Index terms: Musa sp., micropropagation, dibble tubes, acclimatization, ex vitro conditions.

\section{INTRODUÇÃO}

Mudas micropropagadas de bananeira têm sido crescentemente utilizadas e preferidas como material propagativo em virtude de sua qualidade genética e fitossanitária, uniformidade e pela possibilidade de rápida multiplicação e distribuição de novas cultivares para o setor produtivo (Kodym
\& Zapata-Arias, 1999; Rocha, 2005). Adicionalmente, tem-se o fato de que a micropropagação, em escala comercial, já é realidade em diversas regiões do mundo, com destaque para a Europa Ocidental, América do Norte, Ásia, Austrália e Israel (Rocha, 2005). Apesar das vantagens, na maioria das regiões do Brasil, em especial o Norte do País, que representa cerca de $16 \%$ da produção nacional, o uso de mudas micropropagadas para a implantação de novos plantios é ainda restrito, em grande parte

1(Trabalho 038-07). Recebido em: 26-02-2007. Aceito para publicação em: 15-02-2008. Trabalho realizado com o apoio financeiro do Conselho Nacional de Desenvolvimento Científico e Tecnológico - CNPq.

${ }^{2}$ Eng. Agr ${ }^{\circ}$, Mestranda do Curso em Produção Vegetal, UFAC, Rio Branco-AC. E-mail: janiffepoliveira@hotmail.com.

${ }^{3}$ Eng. Agr ${ }^{\circ}$, Doutorando em Agronomia, UFLA, Caixa Postal 37, CEP 37200-000 Lavras-MG, Brasil. E-mail: fredericohenrique@yahoo.com.br ${ }^{4}$ Eng. Agr ${ }^{\circ}$, Pesquisador da Embrapa Recursos Genéticos e Biotecnologia, Núcleo de Recursos Genéticos, Parque Estação Biológica - PqEB - Av. W5 Norte (final), Caixa Postal 02372, CEP 70770-900 Brasília-DF, Brasil. E-mail: jonny@cenargen.embrapa.br. Bolsista de Produtividade em Pesquisa do CNPq. 
pelo elevado custo das mudas, apesar do número de laboratórios e instituições de pesquisa habilitados para a produção deste tipo de muda ter aumentado consideravelmente nos últimos anos. Neste sentido, a otimização das etapas envolvidas no processo constitui-se fator fundamental do processo de produção de material propagativo de alta qualidade, visando a suprir a demanda de uma fruticultura cada vez mais tecnificada (Siviero et al., 2006; Costa et al., 2006; Costa et al., 2007).

Entre as diferentes etapas da micropropagação, a aclimatização é uma das mais importantes. Segundo Wardle et al. (1983), o período de aclimatização, compreendido entre o transplante das plantas produzidas in vitro e o total estabelecimento em casa de vegetação, é complexo e, freqüentemente, ocorrem perdas significativas. Além de serem pouco eficientes fotossinteticamente, as folhas das plantas cultivadas in vitro possuem menor quantidade de ceras epicuticulares do que as plantas crescidas em casa de vegetação ou no campo $\mathrm{e}$, associadas à pouca funcionalidade dos estômatos e À fraca conexão com o sistema vascular, tornam-nas sensíveis a grandes perdas de água por transpiração, podendo levá-las à morte (Sciutti \& Morini, 1993; Ross-Karsten et al., 1998; Pospísilová et al., 1999).

Outro aspecto a considerar na fase de aclimatização referese ao padrão de crescimento das plantas. Isso se deve ao fato de que, ao sofrer mudança abrupta de ambiente, ou seja, passando de condições in vitro para ex vitro, normalmente as plantas apresentam uma parada ou redução do crescimento até que se adaptem às novas condições, podendo levar de dias a semanas até que retornem ao crescimento (Pereira \& Fortes, 2000; Pereira et. al., 2001). Assim, a redução de perdas por morte, associada ao rápido crescimento de mudas na aclimatização são fatores que podem contribuir significativamente para que mudas micropropagadas cheguem ao setor produtivo de forma mais rápida e barata (Pereira \& Fortes, 2004). Para tanto, a escolha adequada de substratos e recipientes específicos para cada espécie é de fundamental importância (Schmitz et al., 2002).

No caso dos substratos, suas propriedades físicas, químicas e biológicas podem facilitar ou limitar a sobrevivência, formação de novas raízes e o conseqüente crescimento das plantas (Fachinello et al., 1995; Calvete et al., 2000; Setubal \& Neto, 2000). Ressalta-se, ainda, que não apenas as propriedades físico-químicas devem ser consideradas na escolha de substratos e materiais que irão compor a mistura, devendo-se observar, também, o custo e sua disponibilidade. Desse modo, o uso de substratos e formulações facilmente disponíveis nos locais de produção das mudas, tais como pó de coco, esterco bovino, casca de arroz carbonizada, bagana de carnaúba, entre outros (Peixoto et al., 2006), são alternativas para a redução dos custos, com resultados positivos no desenvolvimento das plantas (Bezerra \& Rosa, 2002).

Outro fator a ser considerado são os recipientes nos quais as plantas são cultivadas, pois aspectos como o volume do recipiente poderão exercer influência decisiva no desenvolvimento e manutenção do ativo crescimento das plantas durante as etapas de aclimatização e enviveiramento. Segundo Reis et al. (1989), o desempenho no campo é maior, à medida que as dimensões das mudas, por ocasião do plantio, forem maiores. A restrição do sistema radicular limita o crescimento e o desenvolvimento de várias espécies, pela redução da área foliar, altura e produção de biomassa. Ainda segundo estes autores, o pequeno volume dos recipientes, exige, também, a aplicação de doses elevadas de nutrientes, devido às perdas por lixiviação, resultantes da necessidade de regas freqüentes.

O trabalho teve por objetivo avaliar o crescimento de mudas micropropagadas de bananeira durante a aclimatização sob a influência de diferentes substratos e recipientes nas condições da Amazônia Sul-Ocidental.

\section{MATERIAL E MÉTODOS}

O trabalho foi conduzido em área experimental da Embrapa Acre, Rio Branco - AC, com altitude de $160 \mathrm{~m}$, latitude de $9^{\circ} 58^{\prime} 22^{\prime \prime} \mathrm{S}$, longitude de $67^{\circ} 48^{\prime} 40^{\prime \prime} \mathrm{WGr}$, precipitação anual entre 1.800 e $1.900 \mathrm{~mm}$, temperatura média de $25^{\circ} \mathrm{C}$ e umidade relativa média de $85 \%$.

O material vegetal consistiu de brotações de bananeiras procedentes do sexto subcultivo, obtidas do estabelecimento e multiplicação in vitro de ápices caulinares da cultivar Grand Naine (AAA). O meio de cultura utilizado para a multiplicação das brotações foi o MS (Murashige \& Skoog, 1962), acrescido de 4 mg. $L^{-1}$ de BAP ( $\mathrm{N}^{6}$-benzilaminopurina) e solidificado com 5 g. $\mathrm{L}^{-1}$ de ágar, sendo os subcultivos realizados a cada quatro semanas. Para o enraizamento in vitro, as brotações foram mantidas em meio MS desprovido de reguladores de crescimento por quatro semanas.

Os meios de cultura utilizados nas diferentes fases tiveram o pH ajustado para 5,8 $\pm 0,1$ antes da adição do agente geleificante ágar, sendo, em seguida, esterilizados por 15 minutos, a $121^{\circ} \mathrm{C}$ e $1,3 \mathrm{~atm}$ de pressão. Uma vez estabelecidas em frascos de vidro de $250 \mathrm{~mL}$ de capacidade, com $40 \mathrm{~mL}$ de meio de enraizamento, as brotações foram mantidas em sala de crescimento, sob temperatura de $25 \pm 2{ }^{\circ} \mathrm{C}$, fotoperíodo de 16 horas e intensidade luminosa de $30 \mu \mathrm{mol} \cdot \mathrm{m}^{-2} \cdot \mathrm{s}^{-1}$, fornecida por lâmpadas fluorescentes tubulares brancas frias. Decorrida a fase de enraizamento, as plantas foram retiradas dos frascos, individualizadas, lavadas em água corrente para remover o excesso do meio de cultura aderido às raízes, sendo imediatamente transferidas para os tubetes preenchidos com diferentes tipos de substratos.

Os tratamentos consistiram da combinação de dois tipos de tubetes $\left(115 \mathrm{~cm}^{3}\right.$ e $180 \mathrm{~cm}^{3}$ de capacidade) e seis composições de substratos homogeneizados manualmente, sem a adição de fertilizantes, como segue: S1 - terra de encosta; S2 - terra de encosta + esterco bovino $(3: 1 \mathrm{v} / \mathrm{v}) ; \mathrm{S} 3$ - terra de encosta + casca de arroz carbonizada $(3: 1 \mathrm{v} / \mathrm{v}) ; \mathrm{S} 4$ - terra de encosta + esterco bovino + casca de arroz carbonizada $(3: 1: 1 \mathrm{v} / \mathrm{v}) ; \mathrm{S} 5$ - terra de encosta + esterco bovino + casca de arroz carbonizada (3:1:2 v/v), e S6 - terra de encosta + esterco bovino + casca de arroz carbonizada $(3: 1: 3 \mathrm{v} / \mathrm{v})$. Antes da transferência dos substratos para os tubetes, os mesmos foram desinfestados com formol (ácido fórmico) a 2,5\% e vedados com auxílio de um filme de polietileno preto $(100 \mu \mathrm{m})$, por cinco dias consecutivos. Em seguida, retiraram-se amostras dos substratos para análise, sendo 
que a composição química de cada um dos substratos se encontra na Tabela 1 .

O plantio das mudas foi feito em telado, coberto com filme de polietileno transparente $(150 \mu \mathrm{m})$ e sombrite $(50 \%$ de interceptação luminosa), onde permaneceram por um período de 75 dias. A irrigação das plantas foi feita por meio de aspersores, distantes a aproximadamente 1,2 $\mathrm{m}$ de altura, de onde foram acondicionados os tubetes, com vazão nominal de $60 \mathrm{~L} / \mathrm{H} / \mathrm{m}^{2}$, sendo controlados por um temporizador digital (timer). Nas duas primeiras semanas, as mudas foram submetidas a períodos de irrigação a cada três horas, por 15 minutos e, em seguida, a cada 8 horas, também por 15 minutos. Os tubetes foram acondicionados em bandejas suspensas a $0,50 \mathrm{~m}$ do solo do viveiro e, durante crescimento das plantas, não se realizaram tratamentos fitossanitários.

O delineamento experimental foi em blocos casualizados, no esquema de parcelas subdivididas, utilizando-se nas parcelas dos dois tipos de tubetes ( $115 \mathrm{~cm}^{3}$ e $180 \mathrm{~cm}^{3}$ de capacidade) e, nas subparcelas, dos seis tipos de substratos, com quatro repetições e nove plantas por parcela. Quinzenalmente, avaliaramse a percentagem de sobrevivência, a altura da parte aérea e o diâmetro do pseudocaule. A determinação da sobrevivência das plantas foi realizada por contagem do número de plantas mortas após o tempo de aclimatização considerado. A determinação da altura da parte aérea foi feita por meio de medição da região compreendida entre o colo e a inserção da última folha das plantas. Os valores referentes ao diâmetro foram obtidos por medição do pseudocaule a $1 \mathrm{~cm}$ do substrato, com auxílio de um paquímetro. Ao final de 75 dias de avaliação, a determinação das massas fresca e seca da parte aérea e de raízes também foi realizada, coletando-se, ao acaso, três plantas por parcela de cada tratamento, logo após a última avaliação do experimento. Destas plantas, separaram-se as raízes e a parte aérea, sendo o material secado em estufa à temperatura de $65^{\circ} \mathrm{C}$ até peso constante.

Os dados foram submetidos à análise de variância, utilizando o Sistema de Análise Estatística para microcomputadores - SANEST (Zonta \& Machado, 1984), sendo as médias comparadas pelo teste de Tukey, a 5\% de probabilidade. Dados expressos em percentagem (x) foram transformados segundo arco-seno $\mathrm{x} / 100^{0,5}$.

\section{RESULTADOS E DISCUSSÃO}

Pela análise dos substratos, pode-se observar aumento na umidade percentual e nos teores de carbono, nitrogênio, cálcio, fósforo e potássio à medida que a proporção de casca de arroz carbonizada nos substratos contendo esterco foi elevada (Tabela 1). É possível observar ainda que, quando foi feita a análise química do esterco bovino isoladamente, este apresentou os maiores teores de nutrientes, o que pode influenciar sobremaneira na disponibilidade de nutrientes nos substratos que o contêm (Tabela 1). Este fato corrobora Almeida et al. (1988) e Matos et al. (2002), que afirmam que, para uma correta interpretação dos resultados obtidos com o emprego de esterco em substratos, deve-se considerar a composição química do mesmo, uma vez que alterações na composição de substratos pelo uso de esterco proporcionam efeitos benéficos no crescimento vegetativo de mudas.

A sobrevivência das plântulas não foi significativamente influenciada pelos diferentes substratos e tipos de tubetes utilizados, tendo sido observada uma sobrevivência média superior a 91\% (Tabela 2). Para a altura da parte aérea e diâmetro do pseudocaule, o cultivo das plantas em tubetes de maior tamanho promoveu resultados significativamente superiores, com altura média de $30,5 \mathrm{~cm}$ e $11,2 \mathrm{~mm}$, respectivamente. Estes resultados estão em concordância com Neto et al. (2004), segundo os quais o tamanho do recipiente tem grande influência no desenvolvimento de mudas, por proporcionar um bom desenvolvimento do sistema radicular. Provavelmente, o maior volume de substrato nos tubetes maiores e, conseqüentemente, a maior disponibilidade de nutrientes ao longo do tempo e o maior espaço para o crescimento das raízes tenham favorecido positivamente os resultados de crescimento das plantas observados neste experimento.

Apesar de o cultivo em tubetes pequenos $\left(115 \mathrm{~cm}^{3}\right)$ ter proporcionado resultados inferiores em crescimento das plantas que aqueles observados em tubetes de $180 \mathrm{~cm}^{3}$, não houve diferenças na sobrevivência das plantas, sugerindo que seu emprego poderia ser útil em curtos períodos de aclimatização. Constituem-se, portanto, numa alternativa para economia de material, pois uma menor quantidade de substrato é necessária para o preenchimento dos tubetes, além de requererem menor espaço físico, tempo na execução do trabalho e, conseqüentemente, menor custo na produção.

Estudando o comportamento de mudas de abacaxizeiro micropropagadas sob a influência de diferentes substratos e recipientes, Souza Júnior et al. (2001) não observaram superioridade do uso de tubetes grandes em relação a tubetes pequenos. De acordo com seus resultados, o cultivo em tubetes pequenos suplantou os tubetes grandes quanto às variáveis de crescimento da parte aérea e do sistema radicular, exceção observada apenas para o diâmetro do colo. No entanto, de acordo com Reis et al. (1989), a restrição do crescimento de raízes provocada pelo volume do recipiente pode promover o desequilíbrio da razão raízes: parte aérea, alterando as respostas fisiológicas das plantas cultivadas.

Avaliando-se os substratos, incrementos significativos em relação à altura da parte aérea,foram observados apenas entre o substrato S1 e S2 (desprovido e acrescido de esterco, respectivamente), muito embora os substratos contendo esterco bovino tenham apresentado as maiores médias. Já, quanto ao diâmetro de plantas, os melhores resultados foram obtidos nos substratos formulados com esterco bovino (S2, S4, S5 e S6), os quais não diferiram entre si, porém foram estatisticamente superiores aos demais substratos (Tabela 2).

Diante desses resultados, pode-se inferir que a introdução de esterco bovino teve um efeito mais pronunciado sobre o crescimento e a formação de mudas micropropagadas de bananeira do que o incremento na proporção de casca de arroz carbonizada aos substratos. Além disso, entre os substratos contendo casca de arroz carbonizada, pouca contribuição foi 
observada com o aumento deste componente.

Resultados positivos pelo uso da matéria orgânica (esterco bovino) na composição de substratos para a produção de mudas têm sido reportados por vários autores (Sousa, 1994; Verma \& Arya, 1998). De acordo com Verma \& Arya (1998), a matéria orgânica (esterco de curral) possui em seu peso seco basicamente: $0.4-1.5 \% \mathrm{~N}, 0.3-0.9 \%$ de $\mathrm{P}_{2} \mathrm{O}_{5}$ e $0.3-1.9 \% \mathrm{~K}_{2} \mathrm{O}$. Deste, metade é constituída de $\mathrm{N}$ ou $\mathrm{K}$, e $1 / 6$ do fósforo é prontamente solúvel e disponível para as plantas. Soma-se a estas características o fato do húmus ou da matéria orgânica possuírem ainda propriedades de natureza coloidal, decorrentes de sua estrutura orgânica complexa, aliada a uma fina subdivisão de partículas (Raij, 1991). Assim, podem-se obter efeitos benéficos quanto à fertilidade do solo e no estímulo ou não do desenvolvimento de fungos micorrízicos benéficos (Joner \& Jakobsen, 1992; Vejsadova, 1992), além de promover melhor desenvolvimento das raízes (Branzanti et al., 1992). Estudando os efeitos da utilização de fungos micorrízicos e da matéria orgânica na aclimatização de mudas micropropagadas de bananeira cv. Nanicão (AAA), Matos et al. (2002) observaram que, no tratamento sem micorrizas, a presença de matéria orgânica incrementou todas as variáveis avaliadas (altura, diâmetro e número de folhas ativas) em relação a sua ausência, muito embora, para algumas variáveis, não tenham sido observadas diferenças estatísticas quando se adicionou $10 \%$ e $20 \%$ de matéria orgânica.

Trabalhando com mudas micropropagadas de abacaxizeiro cv. Pérola, Moreira et al. (2006) também evidenciaram efeitos positivos da composição de substratos com esterco bovino. Segundo estes autores, as variáveis analisadas relativas à parte aérea $\mathrm{e}, \mathrm{em}$ menor intensidade, as raízes, foram favorecidas pelo uso deste tipo de matéria orgânica. Contrariamente, mudas cultivadas apenas em terra de subsuperfície apresentaram resultados inferiores quando comparados àqueles obtidos com substratos formulados com esterco bovino, evidenciando a necessidade da mistura deste tipo de componente orgânico aos substratos. Peixoto et al. (2006) notaram benefícios advindos da utilização de esterco bovino como componente de substratos para aclimatização de palma forrageira (Opuntia ficus-indica (L.) Mill.) micropropagadas, em que as plantas cultivadas em substratos contendo solo e esterco, nas proporções de 1:1 e 2:1, aos 180 dias, apresentaram os melhores resultados, atingindo $27,82 \mathrm{~cm}$ e $25,49 \mathrm{~cm}$ de altura, além de apresentarem maior número de brotações, com 2,25 e 2,50 por planta, respectivamente.

Embora nenhuma diferença significativa tenha sido observada entre os substratos formulados com terra de encosta e casca de arroz carbonizada e aqueles contendo apenas esterco, pesquisas relatam que a opção pela casca de arroz é, na maioria das vezes, atribuída a sua característica de aumentar a porosidade total do substrato, em razão de sua baixa densidade, permitindo, dessa forma, maior drenagem e aeração do sistema radicular da muda (Hartmann et al., 1990), o que poderia acarretar maior desenvolvimento das raízes e crescimento da parte aérea. Além disso, seu baixo custo e sua grande disponibilidade em regiões onde a orizicultura se encontra presente, são fatores relevantes para que diversos autores o utilizem como constituinte na formulação de substratos (Bellé \& Kämpf, 1994).

Em relação à massa fresca de raízes, parte aérea e total, nenhuma diferença significativa foi verificada entre os substratos quando se empregaram tubetes pequenos $\left(115 \mathrm{~cm}^{3}\right)$. Por outro lado, observou-se comportamento distinto pelo uso de tubetes maiores $\left(180 \mathrm{~cm}^{3}\right)$, em que resultados verificados nos substratos $\mathrm{S} 1$ e S3 foram estatisticamente inferiores àqueles observados em substratos que continham o esterco bovino em sua composição. Em geral, as maiores médias foram verificadas quando se utilizou tubetes grandes $\left(180 \mathrm{~cm}^{3}\right)$ e nos substratos contendo esterco bovino em sua composição (Tabela 3 ).

Para a massa seca de raízes, diferenças significativas entre os substratos só foram verificadas quando se utilizaram tubetes pequenos $\left(115 \mathrm{~cm}^{3}\right)$, embora o substrato contendo terra de encosta e casca de arroz carbonizada (S3) tenha apresentado a menor média. Já em relação à massa seca da parte aérea e total, não se verificou diferença estatística entre os substratos com o uso de tubetes pequenos $\left(115 \mathrm{~cm}^{3}\right)$. Entretanto, reposta significativa das mudas crescendo em diferentes substratos com o emprego de tubetes grandes $\left(180 \mathrm{~cm}^{3}\right)$ foi verificada, com menores médias para o substrato S1 e S3 (Tabela 4).

Avaliando-se as médias, observa-se que o cultivo de plantas de bananeira da cv. Grand Naine nos tubetes maiores e em substratos contendo esterco em sua composição, possibilitou os melhores resultados às variáveis avaliadas neste trabalho (Tabela 4). Observações semelhantes foram reportadas por Matos et al. (2002), segundo os quais, a massa seca de raízes de mudas de bananeira, cv. Nanicão, cultivadas na presença de matéria orgânica, tiveram valores 7,6 vezes superiores àquelas cultivas sem a presença de matéria orgânica. Porém, observaram que, para a área e comprimento radicular específico, as maiores médias foram constatadas sem matéria orgânica. Outro efeito também notado por estes autores pelo uso da matéria orgânica refere-se ao conteúdo total de fósforo na planta, que foi estatisticamente superior na ausência de esterco no substrato.

TABELA 1- Características químicas dos substratos testados e de seus componentes. Embrapa Acre, 2004.

\begin{tabular}{|c|c|c|c|c|c|c|c|c|}
\hline Substrato & Cinzas & Umidade & Carbono & $\mathbf{N}$ & Ca & Mg & $\mathbf{P}$ & $\mathbf{K}$ \\
\hline Esterco & 76,07 & 4,81 & 23,93 & 0,97 & 5,24 & 4,24 & 3,34 & 10,06 \\
\hline CAC & 35,72 & 7,59 & 64,28 & 0,79 & 3,93 & 2,24 & 2,60 & 10,37 \\
\hline S1 & 90,15 & 2,70 & 9,85 & 0,30 & 2,02 & 0,74 & 0,61 & 1,86 \\
\hline $\mathrm{S} 2$ & 88,56 & 2,46 & 11,44 & 0,34 & 2,42 & 1,09 & 0,98 & 2,65 \\
\hline S3 & $\begin{array}{l}80,50 \\
87,49\end{array}$ & 2,40 & 12,51 & 0,32 & 2,24 & 0,74 & 0,67 & 2,19 \\
\hline S4 & 85,62 & 2,68 & 14,38 & 0,40 & 2,70 & 1,16 & 1,07 & 2,93 \\
\hline S5 & 82,13 & 3,13 & 17,87 & 0,49 & 2,73 & 1,62 & 1,19 & 2,67 \\
\hline S6 & 76,46 & 3,70 & 23,54 & 0,55 & 3,04 & 0,97 & 1,37 & 8,12 \\
\hline
\end{tabular}

Médias de três plantas/parcela. Resultados de N, Ca, Mg, K e P foram obtidos com base na matéria seca a $105^{\circ} \mathrm{C}$. Análises realizadas de acordo com Embrapa (1997). CAC: casca de arroz carbonizada; S1: terra de encosta; S2: terra de encosta + esterco bovino (3:1 v/v); S3: terra de encosta + CAC (3:1 $\mathrm{v} / \mathrm{v})$; S4: terra de encosta + esterco bovino + CAC $(3: 1: 1 \mathrm{v} / \mathrm{v}) ; \mathrm{S} 5:$ terra de encosta + esterco bovino + CAC (3:1:2 v/v) e S6: terra de encosta + esterco bovino + CAC $(3: 1: 3 \mathrm{v} / \mathrm{v})$

Rev. Bras. Frutic., Jaboticabal - SP, v. 30, n. 2, p. 459-465, Junho 2008 
TABELA 2 - Taxa de sobrevivência, altura da parte aérea e diâmetro do pseudocaule de mudas micropropagadas de bananeira, cv. Grand Naine (AAA), após 75 dias de aclimatização. Embrapa Acre, 2004.

\begin{tabular}{|c|c|c|c|c|c|c|c|c|c|}
\hline \multirow{2}{*}{ Substratos } & \multicolumn{3}{|c|}{ Sobrevivência (\%) } & \multicolumn{3}{|c|}{ Altura da parte aérea $(\mathrm{cm})$} & \multicolumn{3}{|c|}{ Diâmetro (mm) } \\
\hline & TP* & TG* & Média & $T^{* *}$ & TG* & Média & TP* & TG* & Média \\
\hline S1 & 88,9 & 97,2 & $93,0 \mathrm{a}$ & 21,0 & 25,0 & $23,0 \mathrm{~b}$ & 8,2 & 9,4 & $8,8 \mathrm{~b}$ \\
\hline S2 & 100 & 100 & $100 \mathrm{a}$ & 23,0 & 34,0 & $28,8 \mathrm{a}$ & 9,1 & 12,6 & $10,9 \mathrm{a}$ \\
\hline $\mathbf{S 3}$ & 86,1 & 97,2 & $91,7 \mathrm{a}$ & 19,5 & 27,8 & $23,7 \mathrm{ab}$ & 7,6 & 10,0 & $8,8 \mathrm{~b}$ \\
\hline S4 & 97,2 & 100 & $98,6 \mathrm{a}$ & 22,3 & 31,1 & $26,7 \mathrm{ab}$ & 8,5 & 11,7 & $10,1 \mathrm{a}$ \\
\hline S5 & 100 & 100 & $100 \mathrm{a}$ & 24,0 & 31,8 & $27,9 \mathrm{ab}$ & 9,2 & 12,1 & $10,6 \mathrm{a}$ \\
\hline S6 & 100 & 100 & $100 \mathrm{a}$ & 23,2 & 32,8 & $28,0 \mathrm{ab}$ & 8,9 & 11,2 & $10,1 \mathrm{a}$ \\
\hline Média & $95,4 \mathrm{~A}$ & $99,1 \mathrm{~A}$ & & $22,2 \mathrm{~B}$ & $30,5 \mathrm{~A}$ & & $8,6 \mathrm{~B}$ & $11,2 \mathrm{~A}$ & \\
\hline CV (\%) & & 8,3 & & & 17,3 & & & 6,7 & \\
\hline
\end{tabular}

Médias seguidas por letras distintas dentro de cada item avaliado, minúsculas na vertical e maiúsculas na horizontal, diferem entre si, a $5 \%$ de probabilidade, pelo teste de Tukey. S1: terra de encosta; S2: terra de encosta + esterco bovino (3:1 v/v); S3: terra de encosta + casca de arroz carbonizada $(3: 1 \mathrm{v} / \mathrm{v}) ;$ S4: terra de encosta + esterco bovino + Casca de arroz carbonizada $(3: 1: 1 \mathrm{v} / \mathrm{v})$; S5: terra de encosta + esterco bovino + Casca de arroz carbonizada $(3: 1: 2 \mathrm{v} / \mathrm{v})$ e S6: terra de encosta + esterco bovino + Casca de arroz carbonizada $(3: 1: 3 \mathrm{v} / \mathrm{v})$.

* TP - Tubetes Pequenos $\left(115 \mathrm{~cm}^{3}\right)$; TG - Tubetes Grandes $\left(180 \mathrm{~cm}^{3}\right)$.

TABELA 3 - Massa fresca de raízes, parte aérea e total de mudas micropropagadas de bananeira, cv. Grand Naine (AAA), após 75 dias de aclimatização. Embrapa Acre, 2004.

\begin{tabular}{|c|c|c|c|c|c|c|c|c|c|}
\hline \multirow{2}{*}{ Substratos } & \multicolumn{3}{|c|}{ Massa fresca de Raízes (g)* } & \multicolumn{3}{|c|}{$\begin{array}{l}\text { Massa fresca da Parte Aérea } \\
(\mathrm{g})^{*}\end{array}$} & \multicolumn{3}{|c|}{ Massa fresca total* } \\
\hline & TP** & TG** & Média & $\mathbf{T P} * *$ & TG** & Média & TP** & TG** & Média \\
\hline S1 & $3,6 \mathrm{aB}$ & $6,9 \mathrm{bA}$ & $5,3 \mathrm{~b}$ & $8,0 \mathrm{aB}$ & $17,1 \mathrm{~b} \mathrm{~A}$ & $12,6 \mathrm{~b}$ & $11,5 \mathrm{aB}$ & $24,1 \mathrm{bA}$ & $17,8 \mathrm{~b}$ \\
\hline S2 & $5,5 \mathrm{aB}$ & $11,5 \mathrm{aA}$ & $8,5 \mathrm{a}$ & $12,2 \mathrm{aB}$ & 29,6 aA & $20,9 \mathrm{a}$ & $17,8 \mathrm{aB}$ & $40,7 \mathrm{aA}$ & $29,2 \mathrm{a}$ \\
\hline S3 & 5,0 aA & $6,8 \mathrm{bA}$ & $5,9 \mathrm{~b}$ & $8,6 \mathrm{aB}$ & $18,5 \mathrm{bA}$ & $13,5 \mathrm{~b}$ & $13,5 \mathrm{aB}$ & $25,2 \mathrm{bA}$ & $19,3 \mathrm{~b}$ \\
\hline S4 & $5,4 \mathrm{aB}$ & $12,9 \mathrm{aA}$ & $9,2 \mathrm{a}$ & $11,2 \mathrm{aB}$ & $11,2 \mathrm{aA}$ & $20,6 \mathrm{a}$ & $16,6 \mathrm{aB}$ & $42,9 \mathrm{aA}$ & $29,7 \mathrm{a}$ \\
\hline S5 & $6,1 \mathrm{aB}$ & $13,2 \mathrm{aA}$ & $9,6 \mathrm{a}$ & $11,1 \mathrm{aB}$ & $34,0 \mathrm{aA}$ & $22,6 \mathrm{a}$ & $17,2 \mathrm{aB}$ & $41,3 \mathrm{aA}$ & $29,2 \mathrm{a}$ \\
\hline S6 & $5,4 \mathrm{aB}$ & $11,6 \mathrm{aA}$ & $8,5 \mathrm{a}$ & $10,8 \mathrm{aB}$ & $27,8 \mathrm{aA}$ & $19,3 \mathrm{a}$ & $16,3 \mathrm{aB}$ & $39,4 \mathrm{aA}$ & $27,8 \mathrm{a}$ \\
\hline Média & $5,2 \mathrm{~B}$ & $10,5 \mathrm{~A}$ & & $10,3 \mathrm{~B}$ & $26,2 \mathrm{~A}$ & & $15,5 \mathrm{~B}$ & $35,6 \mathrm{~A}$ & \\
\hline CV (\%) & & 23,1 & & & 15,5 & & & 22,3 & \\
\hline
\end{tabular}

* Médias de três plantas/parcela. Médias seguidas por letras distintas dentro de cada item avaliado, minúsculas na vertical e maiúsculas na horizontal, diferem entre si, a 5\% de probabilidade, pelo teste de Tukey. S1: terra de encosta; S2: terra de encosta + esterco bovino (3:1 v/v); S3: terra de encosta + casca de arroz carbonizada (3:1 v/v); S4: terra de encosta + esterco bovino + Casca de arroz carbonizada (3:1:1 v/v); S5: terra de encosta + esterco bovino + Casca de arroz carbonizada $(3: 1: 2 \mathrm{v} / \mathrm{v})$ e $\mathrm{S} 6$ : terra de encosta + esterco bovino + Casca de arroz carbonizada (3:1:3 v/v)

** TP - Tubetes Pequenos $\left(115 \mathrm{~cm}^{3}\right)$; TG - Tubetes Grandes $\left(180 \mathrm{~cm}^{3}\right)$.

TABELA 4 - Massa seca de raízes, parte aérea e total de mudas micropropagadas de bananeira, cv. Grand Naine (AAA), após 75 dias de aclimatização. Embrapa Acre, 2004.

\begin{tabular}{|c|c|c|c|c|c|c|c|c|c|}
\hline \multirow[t]{2}{*}{ Substratos } & \multicolumn{3}{|c|}{ Massa seca de Raízes (g)* } & \multicolumn{3}{|c|}{$\begin{array}{c}\text { Massa seca da Parte Aérea } \\
(\mathrm{g})^{*}\end{array}$} & \multicolumn{3}{|c|}{ Massa seca total (média) } \\
\hline & TP & TG & Média & TP & TG & Média & TP & TG & Média \\
\hline S1 & 0,9 aA & $0,7 \mathrm{abA}$ & $0,8 \mathrm{a}$ & $1,3 \mathrm{aA}$ & $1,6 \mathrm{bA}$ & $1,4 \mathrm{ab}$ & $1,6 \mathrm{aB}$ & $2,3 \mathrm{abA}$ & $2,0 \mathrm{ab}$ \\
\hline S2 & $0,7 \mathrm{abB}$ & 1,1 aA & 0,9 a & $1,2 \mathrm{aB}$ & $2,3 \mathrm{abA}$ & $1,7 \mathrm{ab}$ & $1,6 \mathrm{aB}$ & $3,3 \mathrm{abA}$ & $2,5 \mathrm{a}$ \\
\hline S3 & $0,3 \mathrm{bA}$ & 0,5 aA & $0,4 \mathrm{~b}$ & $0,8 \mathrm{aB}$ & $1,5 \mathrm{bA}$ & $1,2 \mathrm{~b}$ & $1,1 \mathrm{aB}$ & $2,0 \mathrm{bA}$ & $1,6 \mathrm{~b}$ \\
\hline S4 & $0,4 \mathrm{abB}$ & $1,0 \mathrm{abA}$ & $0,7 \mathrm{ab}$ & $1,1 \mathrm{aB}$ & $2,7 \mathrm{aA}$ & $1,9 \mathrm{a}$ & $1,6 \mathrm{aB}$ & $3,7 \mathrm{aA}$ & $2,6 \mathrm{a}$ \\
\hline S5 & $0,4 \mathrm{abB}$ & $1,0 \mathrm{abA}$ & $0,7 \mathrm{ab}$ & $1,1 \mathrm{aB}$ & $2,7 \mathrm{aA}$ & $1,9 \mathrm{a}$ & $1,5 \mathrm{aB}$ & $3,7 \mathrm{aA}$ & $2,6 \mathrm{a}$ \\
\hline S6 & $0,4 \mathrm{abB}$ & $0,8 \mathrm{abA}$ & $0,6 \mathrm{ab}$ & $0,9 \mathrm{aB}$ & $2,2 \mathrm{abA}$ & $1,6 \mathrm{ab}$ & $1,3 \mathrm{aB}$ & $3,0 \mathrm{abA}$ & $2,2 \mathrm{ab}$ \\
\hline Média & $0,5 \mathrm{~B}$ & $0,9 \mathrm{~A}$ & & $1,1 \mathrm{~B}$ & $2,2 \mathrm{~A}$ & & $1,5 \mathrm{~B}$ & $3,0 \mathrm{~A}$ & \\
\hline CV (\%) & & 36,0 & & & 31,3 & & & 24,9 & \\
\hline
\end{tabular}

* Médias de três plantas/parcela. Médias seguidas por letras distintas dentro de cada item avaliado, minúsculas na vertical e maiúsculas na horizontal, diferem entre si, a 5\% de probabilidade, pelo teste de Tukey. S1: terra de encosta; S2: terra de encosta + esterco bovino (3:1 v/v); S3: terra de encosta + casca de arroz carbonizada $(3: 1 \mathrm{v} / \mathrm{v}) ; \mathrm{S} 4$ : terra de encosta + esterco bovino + Casca de arroz carbonizada $(3: 1: 1 \mathrm{v} / \mathrm{v})$; S5: terra de encosta + esterco bovino + Casca de arroz carbonizada (3:1:2 v/v) e S6: terra de encosta + esterco bovino + Casca de arroz carbonizada (3:1:3 v/v).

** TP - Tubetes Pequenos $\left(115 \mathrm{~cm}^{3}\right)$; TG - Tubetes Grandes $\left(180 \mathrm{~cm}^{3}\right)$. 


\section{CONCLUSÕES}

1- A utilização de tubetes de $115 \mathrm{~cm}^{3}$ e $180 \mathrm{~cm}^{3}$ não influenciam na sobrevivência de mudas de bananeira micropropagadas na fase de aclimatização, após 75 dias de permanência das plantas em viveiro, nas condições da Amazônia Sul-Ocidental.

2- Plantas de bananeira micropropagadas cultivadas em tubetes de $180 \mathrm{~cm}^{3}$ apresentam maior crescimento em altura e diâmetro do pseudocaule, além de maior acúmulo de massas fresca e seca das partes aérea e raízes, durante a aclimatização do que as cultivadas em tubetes de $115 \mathrm{~cm}^{3}$.

3-O substrato composto com terra de encosta, casca de arroz carbonizada e esterco bovino $(3: 1: 1 \mathrm{v} / \mathrm{v})$, devidamente esterilizado, pode ser recomendado para que se obtenha alta eficiência na aclimatização de mudas de bananeira micropropagadas nas condições da Amazônia Sul-Ocidental.

4-O uso de uma fonte de matéria orgânica (esterco bovino) na composição do substrato promove maior crescimento de mudas de bananeira micropropagadas nas condições da Amazônia Sul-Ocidental.

5- O uso de casca de arroz carbonizada na composição de substratos destinados à aclimatização de mudas de bananeiras micropropagadas é opcional, desde que uma fonte de matéria orgânica (esterco bovino) faça parte do substrato.

\section{REFERÊNCIAS}

ALMEIDA, D.L. de; SANTOS, G. de A.; DE-POLLI, H. Manual de adubação para o Estado do Rio de Janeiro. Itaguaí:Universidade Rural, 1988. 179p. (Série Ciências Agrárias, 2).

BELLÉ, S.; KAMPF, A.N. Utilização de casca de arroz carbonizada como condicionador hortícola para um solo orgânico. Pesquisa Agropecuária Brasileira, Brasília, v.29, n.8, p.1265-1271, 1994.

BEZERRA, F.C.; ROSA, M.F. Utilização do pó da casca de cocoverde como substrato para produção de mudas de alface. Fortaleza: Embrapa Agroindústria Tropical, 2002. 4p. (Comunicado Técnico, 71).

BRANZANTI, B.; GIANINAZZI-PEARSON, V.; GIANINAZZI, S.; PREDIERI, S.; BARALDI, R. Influence of artificial substrata on mycorrhization of micropropagated fruit trees in a horticultural system. In: READ, D.J.; LEWIS, D.H.; FITTER, A.H.; ALEXANDER, I.J. (Eds.). Mycorrhizas in ecosystems. Oxford: CAB, 1992. p. 373-374.

CALVETE, E.O.; KÄMPF, A.N.; DAUDT, R. Efeito do substrato na aclimatização ex vitro de morangueiro cv. Campinas, Fragaria $\mathrm{x}$ ananassa Duch. In: KÄMPF, A.N.; FERMINO, M.H. (Ed.). Substrato para plantas: a base da produção vegetal em recipientes. Porto Alegre: Gênesis, 2000. p.257-264.
COSTA, F.H.S.; PEREIRA, J.E.S.; PEREIRA, M.A.A.; OLIVEIRA, J.P. Efeito da interação entre carvão ativado e $\mathrm{N}^{6}$ benzilaminopurina na propagação in vitro de bananeira, cv. Grand Naine (AAA). Revista Brasileira de Fruticultura, Jaboticabal, v.28, p.280-283, 2006

COSTA, F.H.S.; PEREIRA, M.A.A.; OLIVEIRA, J.P.; PEREIRA, J.E.S. Efeito de agentes geleificantes alternativos no meio de cultura no cultivo in vitro de abacaxizeiro e bananeira. Revista Ciência e Agrotecnologia, Lavras, v.31, p. 41-46, 2007.

FACHINELLO, J.C., HOFFMANN, A.; NACHTIGAL, J.C.; KERSTEN, E.; FORTES, G.R.L. Propagação de plantas frutíferas de clima temperado. 2.ed. Pelotas: UFPel, 1995. 179p.

HARTMANN, H. T.; KESTER, D. E.; DAVIES JR, F. T. Plant propagation: principles and practices. $5^{\text {th }}$ ed. Englewood Cliffs: Prentice Hall, 1990. 642p

JONER, E.J.; JAKOBSEN, I. Enhanced growth of external VA mycorrhizal hyphae in soil amended with straw. In: READ, D.J.; LEWIS, D.H.; FITTER, A.H.; ALEXANDER, I.J. (Eds). Mycorrhizas in ecosystems. Oxford:CAB, 1982.p. 387.

KODYM, A.; ZAPATA-ARIAS, F. J. Natural light as na alternative light source for the in vitro culture of banana (Musa acuminate) cv. Grande Naine. Plant Cell, Tissue and Organ Culture, Amsterdam, v.55, n.2, p.141-145, 1999.

MATOS, R.M.B.; SILVA, E.M.R. da; BRASIL, F. da C. Micorriza arbuscular e matéria orgânica na aclimatização de mudas de bananeira, cultivar Nanicão. Bragantia, Campinas, v.61, n.3, p.277283,2002 .

MOREIRA, M.A.; CARVALHO, J.G. de; PASQUAL, M.; FRÁGUAS, C.B.; SILVA, A.B. da. Efeito de substratos na aclimatização de mudas micropropagadas de abacaxizeiro cv. Pérola. Ciência \& Agrotecnologia, Lavras, v.30, n.5, p.875-879, 2006.

MURASHIGE, T.; SKOOG F.A. Revised medium for rapid growth and bio assays with tobacco tissue cultures. Physiologia Plantarum, Copenhagen, v.15, p.473-497, 1962.

NETO, C.P.C.T.; HERNANDEZ, F.F.F.; BEZERRA,F.C.; SOUSA, R.F. de; CAVALCANTI, M.L.F. Efeito de diferentes substratos na aclimatação "ex vitro" de mudas de Violeta Africana (Saintpaulia ionantha Wendl). Revista de Biologia e Ciências da Terra, João Pessoa, v.4, n.2, 2004.

PEIXOTO, M.J.A.; CARNEIRO, M.S. de S.; SOUZA, P.Z.; DINIZ, J.D.N.; SOUTO, J.S.; CAMPOS, F. de A.P. Desenvolvimento de Opuntia ficus-indica (L.) Mill., em diferentes substratos, após micropropagação in vitro. Acta Scientiarum, Maringá, v. 28, n.1, p.17-20, 2006. 
PEREIRA, J.E.S.; FORTES, G.R.L. Desfolhamento e baixa temperatura em plantas micropropagadas de macieira como forma de superar a parada de crescimento durante a aclimatização. Revista Brasileira de Fisiologia Vegetal, Brasília, v.12, n.2, p.135$145,2000$.

PEREIRA, J. E. S. ; FORTES, G.R.L. Produção de mudas pré-básicas de batata por estaquia a partir de plantas micropropagadas. Horticultura Brasileira, Brasília, v. 22, n.2, p.185-191, 2004.

PEREIRA, J.E.S.; FORTES, G.R.L.; SILVA, J.B. da. Efeito da aplicação de baixa temperatura em plantas de macieira sobre o crescimento durante a aclimatização. Pesquisa Agropecuária Brasileira, Brasília, v.36, n.1, p.89-95, 2001.

POSPÍSILOVÁ, J.; TICHÁ, I.; KADLECEK, P.; HAISEL, D.; PLZÁKOVÁ, S. Acclimatization of micropropagated plants to ex vitro conditions. Biologia Plantarum, Prague, v.42, p.481-497, 1999.

RAIJ, B. van. Fertilidade do solo e adubação. Piracicaba: Ceres/ Potafos, $1991.343 \mathrm{p}$.

REIS, G.G., REIS, M.G.F., MAESTRI, M.; XAVIER, A., OLIVEIRA, L.M. Crescimento de Eucalyptus camaldulensis, E. grandis e E. cloeziana sob diferentes níveis de restrição radicular. Revista Árvore, Viçosa, v.13, n.1, p.1-18, 1989.

ROCHA, H.S. Luz e sacarose na micropropagação da bananeira "Prata-Anã": alterações morfoanatômicas. 2005.98 f. Dissertação (Mestrado em Fitotecnia) - Universidade Federal de Lavras, Lavras, 2005.

ROSS-KARSTENS, G.S.; EBERT, G.; LUDDERS, P. Influence of in vitro growth conditions on stomatal density, index and aperture of grape, coffee and banana plantlets. Plant Tissue Culture and Biotechnology, Oxford, v.4, p.21-27, 1998.

SCHMITZ, J.A.K.; SOUZA, P.V.D.; KAMPF, A.N. Propriedades químicas e físicas de substratos de origem mineral e orgânica para o cultivo de mudas em recipientes. Ciência Rural, Santa Maria, v.32, p.937-944, 2002.
SCIUTTI, R.; MORINI, S. Effect of relative humidity in in vitro culture on some growth characteristics of a plum rootstock during shoot proliferation and rooting and on plantlet survival. Advances in Horticultural Science, Firenze, v.7, p.153-156, 1993.

SETUBAL, J.W.; NETO, A.F.C. Efeito de substratos alternativos e tipos de bandejas na produção de mudas de pimentão. Horticultura Brasileira, Brasília, v.18, p.593-594, 2000.

SIVIERO, A.; OLIVEIRA, T.K.; PEREIRA, J.E.S.; SÁ, C.P.; SILVA, S.O. Cultivares de banana resistentes à Sigatoka-negra recomendadas para o Acre. Rio Branco: Embrapa Acre, 2006. 8p. (Circular Técnica, 49).

SOUSA, H.U. de. Efeito de composições e doses de superfosfato simples no crescimento e nutrição de mudas de bananeira (Musa sp.) cv. Mysore obtidas por cultura de meristemas. $1994.88 \mathrm{f}$. Dissertação (Mestrado em Fitotecnia) - Escola Superior de Agricultura de Lavras, Lavras, 1994.

SOUZA JÚNIOR, E.E. de; BARBOZA, S.B.S.C.; SOUZA, L.A.C. Efeitos de substratos e recipientes na aclimatação de plântulas de abacaxizeiro [Ananás comosus (L.) Merril] cv. Pérola. Pesquisa Agropecuária Tropical, Goiânia, v.1, n.2, p.147-151, 2001.

VEJSADOVA, H. The influence of organic and inorganic fertilization on development of indigenous VA fungi in roots of red clover. In: READ, D.J.; LEWIS, D.H.; FITTER, A.H.; ALEXANDER, I.J. (Eds). Mycorrhizas in ecosystems. Oxford: CAB, 1992. p. 406-407.

VERMA, R.K.; ARYA, I.D. Effect of arbuscular mycorrhizal fungal isolates and organic manure on growth and mycorrhization of micropropagated Dendrocalamus asper plantlets and on spore production in their rhizosphere, Mycorrhiza, Dijon, v.8, p.113116, 1998.

WARDLE, K.; DOBBS, E.B.; SHORT, K.C. In vitro acclimatization of aseptically cultured plantlets to humidity. Journal of the American Society for Horticultural Science. Mount Vernon, v.108, n.3, p.386-389, 1983. 